\title{
Indústrias transformadoras e estrutura de capital das PME
}

\section{Manufacturing industries and the capital structure of SMEs}

\author{
Fernanda Matias \\ Universidade do Algarve, Faro, Portugal \\ mfmatias@ualg.pt \\ Letícia Domingues \\ Universidade do Algarve, Faro, Portugal \\ leticiafrdomingues@gmail.com
}

\begin{abstract}
Resumo
Este estudo investiga o efeito das indústrias transformadoras e das características das empresas na estrutura de capital de 14.254 PME portuguesas. Os resultados sugerem que as características das PME (Pequenas e Médias Empresas) industriais têm diferente relevância na forma como as empresas se financiam e, na sua maior parte, são mais consistentes com a teoria da pecking order, colocando a dívida de curto prazo a seguir aos fundos próprios, o que deverá merecer a atenção dos gestores, atendendo a que a dívida de curto prazo acarreta maiores encargos financeiros. Considerando cada uma das indústrias separadamente, a evidência empírica também confere maior consistência à teoria da pecking order. O efeito observado nas indústrias transformadoras prevê que a estrutura de capital das empresas envolvidas não poderá ser exclusivamente explicada pelas características das empresas, mas também pela indústria na qual estão inseridas.
\end{abstract}

Palavras-chave: estrutura de capital; PME; indústrias transformadoras; dados em painel.

\begin{abstract}
This study investigates the effect of the manufacturing industries and the characteristics of the companies on the capital structure of 14,254 Portuguese SMEs. The results suggest that the characteristics of industrial SMEs have different relevance in the way firms finance themselves and, for the most part, are more consistent with the pecking order theory, placing short-term debt next to equity. This should merit the attention of managers, given that short-term debt carries higher financial charges. Considering each of the industries separately, the empirical evidence also confers more consistency to the pecking order theory. The observed effect on the manufacturing industries reveals that the capital structure of the companies concerned cannot be explained solely by the characteristics of the companies, but also by the industry in which they are inserted.
\end{abstract}

Keywords: capital structure; SME; manufacturing; panel data. 


\section{Introdução}

A forma como as empresas se financiam e os determinantes da estrutura de capital são matérias estudadas no âmbito da teoria da estrutura de capital que, não obstante, ter emergido da teoria neoclássica da empresa, desenvolveu-se, especialmente, após a publicação, em 1958, do influente trabalho do teorema da irrelevância de Modigliani e Miller. No que concerne aos determinantes da estrutura de capital, é de mencionar que "although the past 60 years produced a surge of empirical literature on the determinants of capital structure, various authors in this major discipline of corporate finance conclude that the overall picture is rather inconclusive" (Hang, Geyer-Klingeberg, Rathgeber \& Stöckl, 2018: 212), o que sugere a pertinência de aprofundar a sua investigação empírica.

Modigliani e Miller (1958) assumiram no seu estudo pressupostos simplificadores da realidade (por exemplo, a inexistência de impostos, a maximização do valor dos acionistas como único objetivo da empresa, a inexistência de informação assimétrica, etc.) que foram sendo derrogados ao longo do tempo, dando origem às duas principais teorias da estrutura do capital: a teoria do trade-off (TOT) e a teoria da pecking order (POT).

Parte substancial da investigação empírica sobre estrutura de capital tem recaído em empresas de grande dimensão (Kumar, Colombage \& Rao, 2015), em detrimento das PME, que são o motor da maior parte das economias dos países desenvolvidos, dinamizando a criação do emprego e o crescimento económico. Por exemplo, as PME portuguesas em 2016 representavam $99,9 \%$ do total das empresas, $79,8 \%$ do total do emprego e $63,5 \%$ do valor acrescentado (Instituto Nacional de Estatística [INE], 2018). A este respeito, López-Gracia e Sogorb-Mira (2008) defendem que as decisões de financiamento das PME são claramente diferentes das decisões tomadas nas empresas de grande dimensão.

$O$ efeito da indústria nos determinantes das PME tem suscitado interesse na investigação, mas não tem sido objeto de estudo intenso (Kumar et al., 2015). Destacam-se alguns estudos sobre a realidade portuguesa (Serrasqueiro, Armada \& Nunes, 2011; Matias, Baptista \& Salsa, 2015) e de outros países (Jordan, Lowe \& Taylor, 1998; Showalter, 1999; Hall, Hutchinson \& Michaelas, 2000; Voulgaris, Asteriou \& Agiomirgianakis, 2002; Margaritis \& Psillaki, 2010; Zhang, 2010; Degryse, Goeij \& Kappert, 2012). Comparativamente com a generalidade dos estudos, este trabalho investiga além das variáveis financeiras mais comuns, também os efeitos da especificidade, inventários e liquidez com base numa amostra de elevada dimensão (por exemplo, Matias et al., [2015] investigaram uma amostra de 1488 PME, enquanto o presente estudo recai sobre 14.254 PME). Acresce que também dedica alguma atenção às diferenças inter-indústrias e a cada uma das indústrias em particular.

Este trabalho investiga os efeitos das indústrias transformadoras e das características das empresas na estrutura de capital das PME portuguesas, bem como a relevância das teorias da pecking order e do trade-off no âmbito dessas indústrias, com base em modelos de regressão linear múltipla de dados em painel.

Em 2016, as empresas das indústrias transformadoras portuguesas representavam 3,41\% e 10,28\% das empresas individuais e sociedades, respetivamente, enquanto a nível de valor acrescentado bruto contribuíam com 4,63\% nas empresas individuais e $25,15 \%$ nas sociedades (INE, 2018). O estudo baseia-se em dados financeiros de uma amostra final composta por 
14.254 PME das indústrias transformadoras portuguesas, do período compreendido entre 2010 e 2016, tendo-se obtido um painel com 82.036 observações.

Os resultados sugerem que as características das PME industriais têm diferente relevância na forma como as empresas se financiam e na sua maior parte são mais consistentes com a pecking order, colocando a dívida de curto prazo a seguir aos fundos próprios, o que deverá merecer a atenção dos gestores, atendendo a que a dívida de curto prazo acarreta maiores encargos financeiros. Além disso, mostram que os ativos são importantes como garantia no acesso ao crédito de médio e longo prazo, pelo que as empresas mais desprovidas destes colaterais tendem a financiar-se com dívida de curto prazo, o que poderá afetar negativamente a sua liquidez e rendibilidade, tal como referido em Matias et al. (2015). Acresce que a evidência empírica prevê uma relação positiva mais intensa entre o crescimento das empresas e a sua dívida de curto prazo. Estes resultados poderão ser particularmente preocupantes no seio das empresas mais jovens, atendendo à relação negativa esperada entre a idade e a dívida e aos problemas de agência e informação assimétrica entre gestores e credores, comuns nessas empresas.

O efeito observado das indústrias transformadoras parece sugerir que a estrutura de capital das empresas envolvidas não poderá ser exclusivamente explicada pelas características das empresas, mas também pela indústria na qual estão inseridas.

Apresentada a introdução, a secção 2 expõe a revisão da literatura sobre as características financeiras que influenciam a estrutura de capital, bem como o efeito da indústria na estrutura de capital; a secção 3 é reservada à metodologia; a secção 4 apresenta os resultados e sua discussão e na secção 5 encontram-se as conclusões, implicações da pesquisa e limitações.

\section{Revisão da literatura}

A estrutura de capital de uma empresa reflete as suas decisões de financiamento. Em termos de investigação, o seminal trabalho de Modigliani e Miller (1958) constitui um marco decisivo no desenvolvimento das teorias que explicam o nível de dívida da empresa, porquanto foram essencialmente construídas através da derrogação dos pressupostos dos mercados de capitais perfeitos, nomeadamente dos impostos sobre o rendimento das pessoas coletivas e singulares (Modigliani \& Miller, 1963; Miller, 1977; DeAngelo \& Masulis, 1980), dos custos de agência (Jensen \& Meckling, 1976; Jensen, 1986), dos custos de insolvência (Kraus \& Lintzenberger, 1973), dos custos de transação (Fischer, Heinkel \& Zechner, 1989) e dos custos da informação assimétrica (Myers \& Majluf, 1984; Myers, 1984).

Genericamente, as teorias financeiras da estrutura de capital têm sido agregadas em duas teorias genéricas: a teoria do trade-off (TOT) e a teoria da pecking order (POT). ${ }^{1}$

A teoria do trade-off, desenvolvida por Kraus e Litzenberger (1973), defende a existência de uma estrutura ótima de capital que resulta do equilíbrio entre os benefícios e os custos da dívida. Os benefícios da dívida correspondem à dedução das despesas incorridas com a dívida

\footnotetext{
${ }^{1}$ Baker e Wurgler (2002) introduziram a teoria do market timing que explica a estrutura de capital com base na situação dos mercados de capitais. A amostra em estudo agrega somente empresas não cotadas, pelo que esta teoria não será objeto de estudo neste trabalho.
} 
no cálculo dos impostos (Modigliani \& Miller, 1963) e à redução dos custos de agência quando a dívida exerce um papel disciplinador na relação entre os gestores e os acionistas (Jensen, 1986). Os custos da dívida reportam a eventuais custos de falência e aos custos de agência resultantes dos conflitos de interesses entre acionistas e credores (Jensen \& Meckling, 1976). Na sua versão estática, o nível de endividamento é determinado num único período, igualando os custos e os benefícios marginais da dívida (Frank \& Goyal, 2009). Esta versão da teoria do trade-off tem evoluído para uma versão dinâmica, segundo a qual a empresa movese gradualmente no sentido de atingir um objetivo de endividamento.

A teoria da pecking order (Myers, 1984; Myers \& Majluf, 1984) sugere que as empresas se financiam de acordo com uma hierarquia de fontes de financiamento. Atendendo aos custos de informação assimétrica entre gestores e investidores, esta teoria defende que as empresas preferem o autofinanciamento e, caso necessitem de financiamento externo, preferirão o endividamento a capital próprio.

A investigação tem revelado que as teorias TOT e POT não são mutuamente exclusivas e ambas as teorias têm fornecido explicações satisfatórias das decisões de financiamento das empresas (Shyam-Sunder \& Myers, 1999). Não obstante, Kumar et al., (2015) na sua revisão de literatura, concluiu que é notório o predomínio da teoria da pecking order na explicação da estrutura de capital das empresas.

Estas teorias apresentam diferentes explicações da estrutura de capital que têm sido testadas empiricamente, mediante o estudo do impacto das diversas características das empresas no seu nível de dívida, conforme se observa a seguir.

A rendibilidade é uma das principais variáveis explicativas investigadas na literatura, considerada em ambas as teorias, TOT e POT. Não obstante, apresentam predições contraditórias: a TOT prevê uma relação positiva com o endividamento, enquanto a POT defende uma relação negativa. Segundo a POT, as empresas mais rendíveis preferirão financiar os seus investimentos com recursos internos, pelo que sustenta uma relação inversa entre a rendibilidade e o nível de endividamento (Myers, 1984). Acresce que a rendibilidade terá maior impacto negativo na dívida de curto prazo no que na dívida de longo prazo, dado que a menor maturidade da dívida facilita a sua amortização e está associada a custos financeiros mais elevados (Degryse et al., 2012). Por sua vez, de acordo com a TOT, as empresas mais rendíveis dispõem de capacidade acrescida para suportar um maior nível de financiamento com capital alheio e aproveitar o benefício fiscal proporcionado pela dívida (Fama \& French, 2002). Além disso, terão maior capacidade para satisfazer as suas responsabilidades financeiras, pelo que a relação prevista com a dívida é positiva.

Relativamente à tangibilidade, ambas as teorias preveem uma relação positiva com a dívida, embora os fundamentos sejam diferentes. À luz da TOT, particularmente com base em argumentos dos custos de falência, os ativos tangíveis tendo, normalmente, um valor de liquidação mais elevado, suportam maior nível de dívida do que os intangíveis (Harris \& Raviv, 1991; Myers, 1993). Os ativos tangíveis também tendem a atenuar os problemas de agência entre credores e dirigentes (Jensen \& Meckling, 1976; Myers, 1977), dado que é comum na generalidade dos países ocidentais a exigência de garantias aquando da contração de empréstimos de médio e longo prazo. Por sua vez, segundo a POT os problemas da informação assimétrica entre gestores/proprietários e os credores podem ser menorizados 
com a cedência de ativos tangíveis como garantia para obtenção de crédito (Myers, 1977). Acresce que atendendo ao ajustamento da maturidade do ativo e do passivo da empresa, subjacente ao princípio do equilíbrio financeiro, os ativos tangíveis tenderão a afetar de forma diferenciada a maturidade da dívida (Degryse et al., 2012), admitindo-se uma relação positiva com a dívida de longo prazo e negativa com a dívida de curto prazo.

De acordo com a TOT, a dimensão da empresa é encarada como uma proxy inversa dos custos de falência. Para além disso, defende que as maiores empresas serão mais diversificadas (Ang, 1992) e incorrem em menor variabilidade dos seus resultados, o que tende a reduzir os custos indiretos de falência (Fama \& French, 2002). Estas predições conjugam-se no sentido da contração de dívida. Por sua vez, Barnea, Haugen e Senbet (1981) argumentam que os problemas de agência tenderão a acentuar-se quando aumenta a assimetria de informação entre os stakeholders, algo que é particularmente visível nas PME devido ao fraco nível da informação financeira disponibilizada, pelo que de acordo com a POT a relação com a dívida também será positiva.

No que tange ao crescimento da empresa, segundo a POT, é de notar que uma empresa com elevado nível de crescimento, mais facilmente esgotará os seus fundos próprios e consequentemente, recorrerá ao endividamento (Shyam-Sunder \& Myers, 1999), predição não prevista à luz da TOT, segundo a qual o maior crescimento da empresa estará associado a menores problemas da gestão dos fluxos financeiros, a maiores custos de insolvência financeira e de agência da dívida, redundando num menor nível de endividamento (Frank \& Goyal, 2009).

DeAngelo e Masulis (1980) contemplaram no seu modelo de estrutura de capital fontes de poupança fiscal não associada ao endividamento, ou seja, substitutos da dívida como, por exemplo, as depreciações e amortizações, gastos não desembolsáveis que reduzem o rendimento tributável e o crédito fiscal associado ao investimento. Quanto mais elevado for o montante dessas rubricas, menor será a propensão das empresas para se endividarem, porquanto os seus resultados tenderão a revelar-se insuficientes para usufruir do benefício de dívida adicional. Assim, a TOT com base em argumentos fiscais admite uma relação negativa entre referida variável e a dívida.

Em relação ao risco dos resultados, é de notar que quanto maior for a sua variabilidade, maior será a probabilidade de a empresa incorrer em custos de insolvência financeira e mais onerosa se tornará a dívida, pelo que o a TOT prevê uma relação negativa entre o risco e a dívida (Frank \& Goyal, 2009). À luz da informação assimétrica, Leland e Pyle (1977) defenderam que a maior incerteza dos resultados da empresa dificulta o seu endividamento, o que conjugado com o baixo nível da informação financeira, normalmente, disponibilizada ao mercado pelas PME justifica, de acordo com a POT, também uma relação negativa com a dívida.

O conceito de liquidez está associado à facilidade com que os ativos podem ser convertidos em dinheiro. Segundo a POT, as empresas com níveis mais elevados de liquidez disporão de fundos internos acrescidos que utilizarão no financiamento das suas necessidades, pelo que sustentam uma relação negativa entre o endividamento e a liquidez. Num estudo sobre PME portuguesas, Serrasqueiro, Matias e Salsa (2016) concluiram que as empresas com maiores níveis de liquidez encontram-se mais endividadas a médio e longo prazo, mas com menores níveis de dívida total e dívida de curto prazo. 
A variável inventários tem sido investigada empiricamente, como medida alternativa aos ativos tangíveis, especialmente adequada no caso de os ativos apresentarem elevado nível de especificidade (Titman \& Wessels,1988; Colombo, 2001). Os inventários constituirão fonte de garantia no acesso ao crédito bancário, pelo que será de prever uma relação positiva com o nível de endividamento da empresa.

As empresas que oferecem produtos com maior nível de especificidade, segundo Titman e Wessels (1988), suportarão maiores custos em situação de insolvência financeira, dada a dificuldade em encontrar um mercado secundário competitivo para colocação dos seus inventários e equipamentos produtivos, consequentemente, defendeu uma relação negativa entre especificidade dos ativos e endividamento.

As teorias da estrutura de capital não preveem a idade como determinante da estrutura de capital, embora seja investigada empiricamente como proxy da reputação da empresa. $\mathrm{Na}$ revisão de literatura de Kumar et al. (2015), os autores sustentam uma relação com o nível de endividamento de diferente natureza: negativa em países desenvolvidos e positiva em países em desenvolvimento, justificando estas evidências empíricas, mediante a observação de menor diversidade de fontes de financiamento nos países em desenvolvimento e, pelo facto de nesses países a dívida somente estar disponível para empresas de maior longevidade e maduras, já reconhecidas no mercado.

No que concerne aos efeitos das indústrias transformadoras, a TOT defende um rácio de dívida ótimo que pode diferir entre as indústrias. Por sua vez, dado que as indústrias transformadoras têm diferentes características, por exemplo, Andraz (2013) na sua tese de doutoramento concluiu que as indústrias transformadoras apresentam perfis diferenciados de entradas, será de esperar que a relevância das teorias TOT e POT também seja diferente nas várias indústrias transformadoras.

\section{Metodologia}

\subsection{Base de dados, amostra e variáveis}

Os dados utilizados neste trabalho foram extraídos da base de dados SABI (Sistema de Análise de Balanços Ibéricos). Este estudo baseia-se em dados financeiros de uma amostra final composta por 14.254 PME de indústrias transformadoras portuguesas, do período compreendido entre 2010 e 2016, tendo-se obtido um painel com 82.036 observações, após a análise de outliers e de observações influentes. ${ }^{2}$

Foram eliminadas as empresas inativas no período em estudo, as que se apresentavam em situação de falência técnica (capitais próprios negativos), critério comumente utilizado na investigação empírica sobre estrutura de capital, por exemplo Ramalho, Rita e Silva (2018), e as que não dispunham de dados económicos e financeiros num período consecutivo de quatro anos.

\footnotetext{
${ }^{2}$ A identificação de outliers entre as variáveis independentes $(X)$ teve por base as estatísticas resíduos estudantizados (res1) e leverage (lev). Para medir a influência de cada observação na qualidade do ajustamento dos modelos, utilizou-se a estatística leverage.
} 
Tabela 1. Empresas da amostra por indústria transformadora

\begin{tabular}{|c|c|c|c|c|}
\hline \multirow[t]{2}{*}{ Designação } & \multicolumn{2}{|c|}{ Universo } & \multicolumn{2}{|c|}{ Amostra } \\
\hline & $\mathrm{N}^{\circ}$ & $\%$ & $\mathrm{~N}^{0}$ & $\%$ \\
\hline Alimentar & 9428 & 13,04 & 1686 & 11,83 \\
\hline Têxteis & 3661 & 5,07 & 806 & 5,65 \\
\hline Vestuário & 9284 & 12,85 & 1404 & 9,85 \\
\hline Couro & 2696 & 3,73 & 828 & 5,81 \\
\hline Madeira e cortiça & 6579 & 9,10 & 882 & 6,19 \\
\hline Impressão e reprodução & 3024 & 4,18 & 626 & 4,39 \\
\hline Outros produtos minerais & 4669 & 6,46 & 900 & 6,31 \\
\hline Produtos metálicos & 13190 & 18,25 & 2711 & 19,02 \\
\hline Mobiliário e colchões & 5512 & 7,63 & 762 & 5,35 \\
\hline Outras & 11133 & 15,40 & 3008 & 21,10 \\
\hline Reparação, manutenção e instalação & 3097 & 4,29 & 641 & 4,50 \\
\hline Total & 72273 & 100,00 & 14254 & 100,00 \\
\hline
\end{tabular}

Fonte: INE, 2018.

Tabela 2. Variáveis dependentes e independentes

\begin{tabular}{|c|c|c|}
\hline Variáveis & Definição & Medida \\
\hline \multicolumn{3}{|c|}{ Dependentes } \\
\hline $\mathrm{DT}_{\mathrm{i}, \mathrm{t}}$ & Dívida total & Passivo total / ativo total \\
\hline$D_{M L P}, t$ & Dívida a médio e longo prazo & Passivo não corrente / ativo total \\
\hline$D C P_{i, t}$ & Dívida a curto prazo & Passivo corrente / ativo total \\
\hline \multicolumn{3}{|c|}{ Independentes } \\
\hline RENT $_{i, t}$ & Rendibilidade & Resultado antes de juros e impostos / ativo total \\
\hline TANG $_{i, t}$ & Tangibilidade & Ativo tangível / ativo total \\
\hline DIM $_{\mathrm{i}, \mathrm{t}}$ & Dimensão & Logaritmo natural do ativo total \\
\hline CRESC $_{\mathrm{i}, \mathrm{t}}$ & Crescimento anual das Vendas & $\left(\right.$ Vendas $_{i, t}-$ vendas $\left._{i, t-1}\right) /$ vendas $_{i, t-1}$ \\
\hline PFNAD $_{i, t}$ & $\begin{array}{l}\text { Poupança fiscal não associada } \\
\text { à dívida }\end{array}$ & Depreciações e amortizações do período / ativo total \\
\hline $\mathrm{RISCO}_{\mathrm{i}, \mathrm{t}}$ & Risco & $\begin{array}{l}\text { Valor absoluto [(resultado antes de juros e impostos } \mathrm{i}_{\mathrm{i}, \mathrm{t}}-\text { resultado antes de } \\
\left.\left.\text { juros e impostos } \mathrm{i}_{\mathrm{i}, \mathrm{t}-\mathrm{1}}\right) \text { /resultado antes de juros e impostos } \mathrm{s}_{\mathrm{i}, \mathrm{t}-\mathrm{I}}\right]\end{array}$ \\
\hline LIQ $_{\mathrm{i}, \mathrm{t}}$ & Liquidez & Ativo corrente / passivo corrente \\
\hline INVENT $_{i, t}$ & Inventários & Inventários / ativo total \\
\hline ESPEC $_{\mathrm{i}, \mathrm{t}}$ & Especificidade & Custo das mercadorias vendidas e matérias consumidas / vendas \\
\hline$R E P_{i, t}$ & Reputação & Logaritmo natural (ano dos dados -ano da constituição) \\
\hline
\end{tabular}


Tabela 1 apresenta a discriminação da amostra por indústria transformadora e a sua representatividade, tendo como referência o número de empresas existentes em Portugal em 2010. ${ }^{3}$

Observando o peso de cada indústria na amostra com o da população em estudo, não se notam elevadas discrepâncias, sendo que as quatro indústrias mais relevantes (vestuário, alimentar, produtos metálicos e outras) representam sensivelmente o mesmo peso, 59,5\% e $61,8 \%$, respetivamente, no universo e na amostra.

Para estudar os efeitos das indústrias transformadoras e das características das empresas na estrutura de capital das PME portuguesas, recorreu-se a proxies dos determinantes utilizadas frequentemente noutros estudos empíricos. A Tabela 2 apresenta as variáveis dependentes e as independentes, bem como as respetivas medidas.

\subsection{Estimação do modelo}

Os modelos de dados em painel permitem compreender a relação entre as variáveis em estudo ao longo do tempo e relevar a heterogeneidade individual, o que os torna mais vantajosos do que os modelos para dados seccionais. O modelo de regressão linear múltipla de dados em painel utilizado neste estudo é o seguinte:

$Y_{i t}=\beta X_{i t}+\alpha_{i}+\mu_{i t}, \quad \mathrm{i}=1, \ldots, 14.254 \quad \mathrm{t}=2010, \ldots, 2016$

Sendo que $X_{i t}$ contém as variáveis observáveis que se alteram ao longo de i mas não de $t$, variáveis que se alteram ao longo de t mas não de i e variáveis que se alteram ao longo de i e de t; $\alpha_{i}$ mede o efeito individual não observado e $\mu_{i t}$ representa o erro idiossincrático, variando ao longo de i e de t.

O método de estimação é validado através de vários testes, Wald Modificado (teste à heterocedasticidade), Multiplicador de Lagrange de Breusch e Pagan (LM) (teste aos efeitos individuais das empresas), Hausman (teste de correlação entre os efeitos individuais e as variáveis independentes) e Wooldridge (teste à autocorrelação de primeira ordem dos resíduos).

\section{Resultados}

\subsection{Estatísticas descritivas}

A Tabela 3 apresenta as estatísticas descritivas das variáveis dependentes e independentes da amostra total. As PME industriais financiam-se com maior percentagem de capital alheio, especialmente com dívida de curto prazo (72\% do total da dívida), o que pode ser observado em todas as indústrias, conforme Tabela 4. Apresentam uma rendibilidade do ativo média de

\footnotetext{
3 Na classificação portuguesa das atividades económicas, revisão 3 (CAE Rev. 3), as indústrias transformadoras inserem-se na secção C. Atendendo ao seu elevado nível de desagregação, procedeu-se à agregação das indústrias com base numa adaptação da metodologia adotada pela base de dados Pordata, base de dados com estatísticas oficiais sobre o país e a Europa, lançada em 2010 e disponível em http://www.pordata.pt/.
} 
$5,4 \%$. Os seus ativos tangíveis representam, em média, $26 \%$ do ativo total, enquanto os inventários constituem $16 \%$ do ativo. A dimensão média das PME é de cerca de 749,4 milhares de euros.

As vendas cresceram em média 7,1\%. As depreciações e amortizações do período atingem, em média, $4,3 \%$ do ativo total. Cerca de $42 \%$ do valor das vendas é canalizado para cobrir o custo das mercadorias vendidas e matérias consumidas. A idade média das empresas é de 16 anos. $O$ ativo corrente mais do que duplica o passivo corrente. Observando os valores dos desvios padrões, é de destacar a forte dispersão na variabilidade do RAJI. ${ }^{4}$

Tabela 3. Estatísticas descritivas das indústrias transformadoras (amostra total)

\begin{tabular}{|l|c|c|c|}
\hline \multicolumn{1}{|c|}{ Varável } & Média & Desvio Padrão & Mediana \\
\hline DT $_{\mathrm{i}, \mathrm{t}}$ & 0,5740 & 0,2184 & 0,6006 \\
\hline DMLP $_{\mathrm{i}, \mathrm{t}}$ & 0,1611 & 0,1597 & 0,1222 \\
\hline DCP $_{\mathrm{i}, \mathrm{t}}$ & 0,4130 & 0,2042 & 0,3951 \\
\hline RENT $_{\mathrm{i}, \mathrm{t}}$ & 0,0537 & 0,0752 & 0,0395 \\
\hline TANG $_{\mathrm{i}, \mathrm{t}}$ & 0,2625 & 0,2009 & 0,2206 \\
\hline DIM $_{\mathrm{i}, \mathrm{t}}$ & 2,8747 & 0,6528 & 2,8217 \\
\hline CRESC $_{\mathrm{i}, \mathrm{t}}$ & 0,0710 & 0,2792 & 0,0343 \\
\hline PFNAD $_{\mathrm{i}, \mathrm{t}}$ & 0,0430 & 0,0326 & 0,0362 \\
\hline RISCO $_{\mathrm{i}, \mathrm{t}}$ & 1,2701 & 2,4353 & 0,5361 \\
\hline LIQ $_{\mathrm{i}, \mathrm{t}}$ & 2,3728 & 1,9814 & 1,7162 \\
\hline INVENT $_{\mathrm{i}, \mathrm{t}}$ & 0,1616 & 0,1650 & 0,1103 \\
\hline ESPEC $_{\mathrm{i}, \mathrm{t}}$ & 0,4165 & 0,2139 & 0,4250 \\
\hline REP $_{\mathrm{i}, \mathrm{t}}$ & 1,2021 & 0,3236 & 1,2304 \\
\hline
\end{tabular}

Nota: As variáveis encontram-se definidas na Tabela 2.

Considerando as diversas indústrias transformadoras, a Tabela 4 sugere a existência de diferenças estatisticamente significativas entre as médias das variáveis dependentes.

Tabela 4. Média das variáveis de endividamento, por indústria

\begin{tabular}{|l|c|c|c|}
\hline & $\mathbf{D T}_{\mathbf{i}, \mathbf{t}}$ & $\mathbf{D M L P}_{\mathbf{i}, \mathbf{t}}$ & $\mathbf{D C P}_{\mathbf{i}, \mathbf{t}}$ \\
\hline Alimentar & 0,5570 & 0,1776 & 0,3794 \\
\hline Têxteis & 0,5840 & 0,1582 & 0,4258 \\
\hline Vestuário & 0,5909 & 0,1516 & 0,4392 \\
\hline Couro & 0,6106 & 0,1306 & 0,4801 \\
\hline Madeira e cortiça & 0,5802 & 0,1600 & 0,4203 \\
\hline Impressão e reprodução & 0,5831 & 0,1887 & 0,3944 \\
\hline Outros produtos minerais & 0,5674 & 0,1853 & 0,3821 \\
\hline Produtos metálicos & 0,5810 & 0,1630 & 0,4180 \\
\hline Mobiliário e colchões & 0,6146 & 0,1760 & 0,4386 \\
\hline Outras & 0,5528 & 0,1546 & 0,3982 \\
\hline
\end{tabular}

\footnotetext{
${ }^{4}$ A matriz de correlações mostra, a nível das variáveis independentes, que a generalidade dos coeficientes de correlação é inferior a 30\%, pelo que de acordo com Gujarati e Porter (2010) o problema da colinearidade entre essas variáveis não será preocupante.
} 


\begin{tabular}{|l|c|c|c|}
\hline & $\mathbf{D T}_{\mathbf{i}, \mathbf{t}}$ & $\mathbf{D M L P}_{\mathbf{i}, \mathbf{t}}$ & $\mathbf{D C P}_{\mathbf{i}, \mathbf{t}}$ \\
\hline Reparação, manutenção e instalação & 0,5310 & 0,1286 & 0,4024 \\
\hline $\begin{array}{l}\text { One-way analysis of variance } \\
\text { F-statistic }\end{array}$ & $74,07 * * *$ & $76,09 * * *$ & $131,86 * * *$ \\
\hline Kruskal-Wallis & $694,90 * * *$ & $686,68 * * *$ & $1282,26 * * *$ \\
\hline
\end{tabular}

Notas:

1. As variáveis encontram-se definidas na tabela 2.

2. *** Indica um nível de significância de $1 \%$.

\subsection{Resultados dos modelos}

As Tabelas 5, 6 e 7 apresentam os resultados dos modelos de dados em painel explicativos dos níveis de endividamento para as indústrias transformadoras da amostra total. Para cada uma das indústrias transformadoras também foi estimado um modelo. ${ }^{5}$

Tabela 5. Estimadores do endividamento total (amostra total)

\begin{tabular}{|c|c|c|c|}
\hline \multirow[b]{2}{*}{ Variável dependente } & \multicolumn{3}{|c|}{ Dívida total } \\
\hline & Efeitos aleatórios & Efeitos fixos & $\begin{array}{c}\text { Efeitos fixos } \\
\text { (AR1) }\end{array}$ \\
\hline RENT $_{i, t}$ & $-0,4133^{* * *}$ & $-0,4184^{* * *}$ & $-0,3774 * * *$ \\
\hline TANG $_{i, t}$ & $0,0273^{* * *}$ & 0,0113 & $-0,0127 * * *$ \\
\hline$D^{\prime} M_{i, t}$ & $0,0553^{* * *}$ & $0,1547 * * *$ & $0,3663^{* * *}$ \\
\hline CRESC $_{i, t}$ & $0,0379 * * *$ & $0,0351 * * *$ & $0,0196 * * *$ \\
\hline PFNAD $_{\mathrm{i}, \mathrm{t}}$ & $-0,2566 * * *$ & $-0,145 * * *$ & $-0,0723^{* * *}$ \\
\hline RISCO $_{i, t}$ & $0,0013^{* * *}$ & $0,0015 * * *$ & $0,0008 * * *$ \\
\hline LIQ $_{\mathrm{i}, \mathrm{t}}$ & $-0,0339 * * *$ & $-0,0289 * * *$ & $-0,0189 * * *$ \\
\hline INVENT $_{\mathrm{i}, \mathrm{t}}$ & $0,0423 * * *$ & $0,0198 * * *$ & $0,0195 * * *$ \\
\hline ESPEC $_{i, t}$ & $0,0407 * * *$ & $0,0392 * * *$ & $0,0218 * * *$ \\
\hline$R E P_{i, t}$ & $-0,2093 * * *$ & $-0,3126 * * *$ & $-0,2427^{* * *}$ \\
\hline Alimentar & $-0,0055$ & & \\
\hline Têxtil & $0,0273 * * *$ & & \\
\hline Vestuário & $0,0551 * * *$ & & \\
\hline Couro & $0,0495^{* * *}$ & & \\
\hline Madeira e cortiça & $0,0271 * * *$ & & \\
\hline Impressão e reprodução & $0,0575 * * *$ & & \\
\hline Outros produtos minerais & 0,0031 & & \\
\hline Produtos metálicos & $0,0244^{* * *}$ & & \\
\hline Mobiliário e colchões & $0,0381 * * *$ & & \\
\hline Outras & 0,0025 & & \\
\hline Reparação, manutenção e instalação & omitida & & \\
\hline Efeito da indústria & $243,31 * * *$ & & \\
\hline Efeito do tempo & $186,95 * * *$ & & \\
\hline $\mathbf{R}^{2}$ & $0,3417 * * *$ & $0,3511 * * *$ & $0,3978 * * *$ \\
\hline $\mathbf{F}$ & & $1121,77^{* * *}$ & $3568,44^{* * *}$ \\
\hline
\end{tabular}

${ }^{5}$ Os resultados destes modelos não serão apresentados, dado que o artigo ficaria demasiado extenso, mas poderão ser disponibilizados. 


\begin{tabular}{|l|c|c|c|}
\hline \multicolumn{2}{|c|}{ Variável dependente } & \multicolumn{2}{c|}{ Dívida total } \\
\cline { 2 - 4 } & Efeitos aleatórios & Efeitos fixos & $\begin{array}{c}\text { Efeitos fixos } \\
\text { (AR1) }\end{array}$ \\
\hline Wald $\left(\boldsymbol{x}^{\mathbf{2}}\right)$ & $17987,92^{* * *}$ & & \\
\hline Wald modificado $\left(\boldsymbol{x}^{\mathbf{2}}\right)$ & & $3,4 \mathrm{e}+35^{* * *}$ & \\
\hline LM $\left(\boldsymbol{x}^{\mathbf{2}}\right)$ & $95430,42^{* * *}$ & & \\
\hline Hausman Robusto $\left(\boldsymbol{x}^{\mathbf{2}}\right)$ & & $10071,08^{* * *}$ & \\
\hline Wooldridge $\left(\boldsymbol{x}^{\mathbf{2}}\right)$ & $5808,51^{* * *}$ & & \\
\hline
\end{tabular}

Notas:

1. A heterocedasticidade foi controlada através do estimador robusto das variâncias em todos os modelos, exceto no modelo Efeitos fixos (AR1).

2. *** Indica um nível de significância de $1 \%$ ** indica um nível de significância de $5 \%$ e *indica um nível de significância de $10 \%$.

3. F é um teste de significância conjunta dos coeficientes específicos estimados das empresas. É assintoticamente distribuído em $\mathrm{N}(0,1)$ sob a hipótese nula de ausência de relação.

4. Wald é um teste de significância conjunta dos valores dos coeficientes específicos estimados das empresas. É assintoticamente distribuído em $\chi^{2}$ sob a hipótese nula de ausência de relação.

5. O teste Wald Modificado testa a variância dos termos de erro. É assintoticamente distribuídos em $\chi^{2}$ sob a hipótese nula de homocedasticidade.

6. O teste LM testa a significância estatística dos efeitos individuais. É assintoticamente distribuído em $\chi^{2}$ sob a hipótese nula de ausência de significância.

7. O teste de Hausman testa a correlação entre os efeitos individuais e as variáveis independentes. É assintoticamente distribuído em $\chi^{2}$ sob a hipótese nula de ausência de correlação com as variáveis independentes.

8. O teste de Wooldridge testa a autocorrelação de primeira ordem dos resíduos em dados em painel. É distribuído em $\mathrm{N}(0,1)$ sob a hipótese nula de ausência de autocorrelação de primeira ordem. 
Tabela 6. Estimadores do endividamento de médio e longo prazo (amostra total)

\begin{tabular}{|c|c|c|c|}
\hline \multirow[b]{2}{*}{ Variável dependente } & \multicolumn{3}{|c|}{ Dívida a médio e longo prazo } \\
\hline & Efeitos aleatórios & Efeitos fixos & $\begin{array}{c}\text { Efeitos fixos } \\
\text { (AR1) }\end{array}$ \\
\hline RENT $_{i, t}$ & $-0,1996 * * *$ & $-0,2012 * * *$ & $-0,1816 * * *$ \\
\hline TANG $_{\mathrm{i}, \mathrm{t}}$ & $0,3563^{* * *}$ & $0,3387 * * *$ & $0,3287 * * *$ \\
\hline$D_{I} M_{i, t}$ & $0,0297 * * *$ & $0,1157^{* * *}$ & $0,1595 * * *$ \\
\hline CRESC $_{i, t}$ & $0,0122 * * *$ & $0,0105 * * *$ & $0,0062 * * *$ \\
\hline PFNAD $_{\mathrm{i}, \mathrm{t}}$ & $-0,2179 * * *$ & $-0,1575 * * *$ & $-0,1407 * * *$ \\
\hline RISCO $_{i, t}$ & $0,0005^{* * *}$ & $0,0006 * * *$ & $0,0004 * * *$ \\
\hline LIQ $_{i, t}$ & $0,0245^{* * *}$ & $0,0287 * * *$ & $0,0313 * * *$ \\
\hline INVENT $_{\mathrm{i}, \mathrm{t}}$ & $0,0327 * * *$ & 0,0074 & $-0,0045$ \\
\hline ESPEC $_{i, t}$ & $-0,0234 * * *$ & $-0,0234 * * *$ & $-0,0326 * * *$ \\
\hline REP $P_{i, t}$ & $-0,0849 * * *$ & $-0,1013^{* * *}$ & $-0,2422 * * *$ \\
\hline Alimentar & 0,0098 & & \\
\hline Têxtil & $0,0241 * * *$ & & \\
\hline Vestuário & $0,0331 * * *$ & & \\
\hline Couro & $0,0205^{* * *}$ & & \\
\hline Madeira e cortiça & $0,0251 * * *$ & & \\
\hline Impressão e reprodução & $0,0423^{* * *}$ & & \\
\hline Outros produtos minerais & $0,0142 * *$ & & \\
\hline Produtos metálicos & $0,0243^{* * *}$ & & \\
\hline Mobiliário e colchões & $0,0368 * * *$ & & \\
\hline Outras & 0,0085 & & \\
\hline Reparação, manutenção e instalação & omitida & & \\
\hline Efeito da indústria & $90,19 * * *$ & & \\
\hline Efeito do tempo & $52,00 * * *$ & & \\
\hline $\mathbf{R}^{2}$ & $0,1808 * * *$ & $0,1917 * * *$ & $0,2182 * * *$ \\
\hline $\mathbf{F}$ & & $465,10 * * *$ & $1507,69 * * *$ \\
\hline Wald $\left(x^{2}\right)$ & $6855,48 * * *$ & & \\
\hline Wald modificado $\left(x^{2}\right)$ & & $7,0 e+37 * * *$ & \\
\hline $\operatorname{LM}\left(x^{2}\right)$ & $71572,59 * * *$ & & \\
\hline Hausman Robusto $\left(x^{2}\right)$ & & $2235,24 * * *$ & \\
\hline Wooldridge $\left(x^{2}\right)$ & $2161,86 * * *$ & & \\
\hline
\end{tabular}

Nota: Ver Tabela 5 . 
Tabela 7. Estimadores do endividamento de curto prazo (amostra total)

\begin{tabular}{|c|c|c|c|}
\hline \multirow[b]{2}{*}{ Variável dependente } & \multicolumn{3}{|c|}{ Dívida a curto prazo } \\
\hline & Efeitos aleatórios & Efeitos fixos & $\begin{array}{c}\text { Efeitos fixos } \\
\text { (AR1) }\end{array}$ \\
\hline RENT $_{i, t}$ & $-0,2198 * * *$ & $-0,2172 * * *$ & $-0,1969 * * *$ \\
\hline TANG $_{\mathrm{i}, \mathrm{t}}$ & $-0,3280 * * *$ & $-0,3274 * * *$ & $-0,3281 * * *$ \\
\hline$D_{I} M_{i, t}$ & $0,0087 * * *$ & $0,0391 * * *$ & $0,1840 * * *$ \\
\hline CRESC $_{i, t}$ & $0,0264 * * *$ & $0,0246 * * *$ & $0,0170 * * *$ \\
\hline PFNAD $_{i, t}$ & $-0,0409 *$ & 0,0120 & $0,1260 * * *$ \\
\hline RISCO $_{i, t}$ & $0,0008 * * *$ & $0,0008 * * *$ & $0,0006 * * *$ \\
\hline LIQ $i, t$ & $-0,0619 * * *$ & $-0,0576 * * *$ & $-0,0522 * * *$ \\
\hline INVENT $_{\mathrm{i}, \mathrm{t}}$ & $0,0229 * * *$ & $0,0123^{*}$ & $0,0380 * * *$ \\
\hline ESPEC $_{i, t}$ & $0,0695 * * *$ & $0,0626 * * *$ & $0,0740 * * *$ \\
\hline REP $P_{i, t}$ & $-0,1152 * * *$ & $-0,2112 * * *$ & $-0,0226 * * *$ \\
\hline Alimentar & $-0,0148 * * *$ & & \\
\hline Têxtil & 0,0039 & & \\
\hline Vestuário & $0,0190 * * *$ & & \\
\hline Couro & $0,0281 * * *$ & & \\
\hline Madeira e cortiça & 0,0002 & & \\
\hline Impressão e reprodução & $0,0133^{* *}$ & & \\
\hline Outros produtos minerais & $-0,0084$ & & \\
\hline Produtos metálicos & $-0,0002$ & & \\
\hline Mobiliário e colchões & $-0,0020$ & & \\
\hline Outras & $-0,0040$ & & \\
\hline Reparação, manutenção e instalação & omitida & & \\
\hline Efeito da indústria & $135,96 * * *$ & & \\
\hline Efeito do tempo & $222,97 * * *$ & & \\
\hline $\mathbf{R}^{2}$ & $0,4459 * * *$ & $0,4468 * * *$ & $0,4020 * * *$ \\
\hline $\mathbf{F}$ & & $1059,86 * * *$ & $3621,82 * * *$ \\
\hline Wald $\left(x^{2}\right)$ & $17707,49 * * *$ & & \\
\hline Wald modificado $\left(x^{2}\right)$ & & $4,3 e+36 * * *$ & \\
\hline $\operatorname{LM}\left(x^{2}\right)$ & $58232,06 * * *$ & & \\
\hline Hausman Robusto $\left(x^{2}\right)$ & & $1860,84^{* * *}$ & \\
\hline Wooldridge $\left(x^{2}\right)$ & $2141,78^{* * *}$ & & \\
\hline
\end{tabular}

Nota: Ver Tabela 5 .

Conforme se observa nas Tabelas 5, 6 e 7 para cada uma das variáveis dependentes, a rejeição da hipótese de variância constante, mediante os resultados do teste de Wald modificado, conduziu à necessidade de corrigir a heterocedasticidade, introduzindo um estimador robusto das variâncias nos modelos de efeitos aleatórios e de efeitos fixos. Observando os resultados do teste de efeitos individuais (LM), conclui-se que os modelos obtidos através do método dos mínimos quadrados ordinários não são os mais adequados. Isto significa que existem características individuais explicativas do nível de dívida das empresas das indústrias transformadoras que não são medidas pelas variáveis independentes consideradas. Prosseguindo com a análise, calculou-se o teste de Hausman, cujos resultados conduzem à rejeição do modelo de efeitos aleatórios, significando que os efeitos individuais não observáveis já referidos, estão correlacionados com as variáveis independentes. Os resultados do teste Wooldridge sugerem a rejeição da hipótese de 
ausência de autocorrelação de $1 .^{\text {a }}$ ordem, pelo que se apresentam também os modelos de efeitos fixos, admitindo autocorrelação (AR1). Este procedimento de análise foi adotado também nos modelos ajustados para cada uma das indústrias transformadoras sendo que, em cada uma das indústrias, o modelo de efeitos fixos (AR1) também se revelou como o mais ajustado.

Atendendo ao exposto nas Tabelas 5, 6 e 7, são de realçar os seguintes resultados:

- O endividamento total e o endividamento de curto prazo são as variáveis dependentes mais bem explicadas pelo conjunto de fatores considerados, com um coeficiente de determinação $\left(R^{2}\right)$, respetivamente, de o,3978 e de 0,4020 (modelos AR1);

- Relativamente aos determinantes do endividamento total, do endividamento de curto prazo e do endividamento de médio e longo prazo, todos os coeficientes das variáveis estudadas apresentam-se estatisticamente significativos com um nível de significância de 1\% (modelo AR1), exceto o coeficiente da variável inventários que não é estatisticamente significativo na explicação da dívida de médio e longo prazo;

- Atendendo à magnitude dos coeficientes, as variáveis rendibilidade, reputação e dimensão, são as de maior impacto no nível de endividamento total, as duas primeiras com efeito negativo, enquanto a dimensão tem efeito positivo. $\mathrm{Na}$ explicação do nível de dívida de curto prazo, mais bem explicado neste estudo, as variáveis tangibilidade, rendibilidade e dimensão são as que têm maior poder explicativo, as duas primeiras com efeito negativo, enquanto a dimensão tem efeito positivo. Por último, as variáveis tangibilidade, dimensão, reputação e rendibilidade são as de maior poder explicativo do endividamento de médio e longo prazo, sendo que as duas primeiras têm influência positiva enquanto as duas últimas têm impacto negativo;

- As diferenças inter-indústrias são evidentes. Grande parte das indústrias transformadoras têm uma estrutura de capital diferente (dummies das indústrias são significativas), comparativamente com a indústria base, no que concerne à dívida total e à dívida de médio e longo prazo;

- Os efeitos do tempo e da indústria são estatisticamente significativos, com um nível de significância de $1 \%$.

\subsection{Discussão dos resultados}

Os resultados obtidos sugerem que as empresas das indústrias transformadoras que geram maior nível de rendibilidade dos seus ativos, apresentam menores níveis de dívida conferindo suporte à POT, tal como no estudo de Degryse et al. (2012). Idêntico comportamento foi observado em cada uma das indústrias. Acresce que a rendibilidade tem maior impacto negativo na dívida de curto prazo do que na dívida de maior maturidade, o que poderá ser explicado pelo facto de a dívida de curto prazo implicar custos financeiros mais elevados. 
O nível de tangibilidade das empresas afeta a maturidade da dívida. Aquelas que têm maior nível de ativos tangíveis apresentam maior peso de endividamento de médio e longo prazo. Com efeito, a estrutura dos ativos dessas empresas contribuirá para atenuar os problemas de agência e de informação assimétrica entre credores e dirigentes. As PME industriais com menor peso de ativos tangíveis endividam-se mais a curto prazo, não obstante os maiores custos financeiros que lhes estão associados. Estes resultados foram evidenciados em cada uma das indústrias estudadas, com uma única exceção, a indústria do vestuário, que mostra uma relação positiva também com a dívida de curto prazo, e sustentam as teorias TOT e POT, à semelhança do estudo de Palacín-Sánchez, Ramírez-Herrera e Pietro (2013) e de Matias et al. (2015).

As PME industriais de maior dimensão parecem utilizar mais dívida, independentemente da sua maturidade. Este comportamento notou-se em todas as indústrias investigadas. Estes resultados suportam ambas as teorias e reforçam a evidência sobre os problemas de informação assimétrica e de agência com que se deparam as empresas de menor dimensão, aquando da obtenção de crédito. Os resultados corroboram os de Degryse et al. (2012) e de Serrasqueiro et al. (2016).

O crescimento das PME industriais em termos de volume de vendas está positivamente associado com o endividamento, independentemente da maturidade da dívida. As empresas com menor nível de crescimento terão menor necessidade de capital alheio, tal como previsto pela POT. Considerando cada uma das indústrias, as relações evidenciadas também são positivas em todas as variáveis de dívida, mas em sete indústrias não são estatisticamente significativas em relação à dívida de médio e longo prazo. Na investigação empírica é mais comum encontrar relações estatisticamente significativas quando o crescimento é medido através dos ativos. Não obstante, Hall et al. (2000) e Hall, Hutchinson e Michaelas (2004) concluíram pela existência de uma relação positiva entre o crescimento das vendas e o endividamento a curto prazo.

De acordo com os resultados, as empresas com maiores níveis de poupança fiscal não associada à dívida registam menores níveis de endividamento total e de médio e longo prazo, tal como previsto pela TOT. Assim, essas empresas perspetivam usufruir de menores benefícios fiscais decorrentes do capital alheio, pelo que terão menor propensão para se endividarem. A nível de cada uma das indústrias em particular, nota-se que em três delas a relação não é estatisticamente significativa com qualquer variável de endividamento (outros produtos minerais, mobiliário e colchões e reparação, manutenção e instalação).

A variabilidade dos resultados como medida do risco do incumprimento parece ser fator relevante na estrutura de capital das PME industriais, mas ao contrário do sugerido pelas teorias, apresenta uma relação positiva com qualquer uma das variáveis de dívida, embora os coeficientes sejam de muito fraca magnitude, tal como no estudo de Michaelas, Chittenden e Poutziouris (1999). A nível de indústrias, observa-se que na sua maior parte não apresentam relações estatisticamente significativas com a dívida, independentemente da sua maturidade.

A natureza da relação entre a liquidez e o endividamento depende da maturidade da dívida utilizada. As empresas cujos ativos correntes representam uma maior proporção dos seus passivos correntes parecem apresentar-se menos endividadas e com menor dívida de curto prazo. Estes resultados conferem suporte à POT. Este comportamento foi observado 
em cada uma das indústrias. Contudo, a relação é positiva com a dívida de médio e longo prazo. Idêntico resultado foi obtido por Serrasqueiro et al. (2016).

A conjugação de relação positiva entre o nível de inventários e a dívida de curto prazo, permite concluir que nas indústrias se observa o princípio conducente ao equilíbrio financeiro, ou seja, o do alinhamento liquidez/exigibilidade. Aparentemente os inventários não desempenham a sua função de colateral no acesso ao crédito, prevista por Colombo (2001). Nalgumas indústrias a variável inventários não parece ser determinante da estrutura de capital (Couro, impressão e reprodução e reparação, manutenção e instalação).

A especificidade do negócio mostra uma relação negativa com o endividamento de médio e longo prazo como esperado, porquanto a especificidade do negócio estará associada a maiores custos em situação de insolvência e, por conseguinte, maior risco. Pelo contrário, a relação observada com a dívida de curto prazo é positiva. Segundo Matias et al. (2015), como a variável também fornece informação sobre a margem industrial de vendas, as empresas caracterizadas por colocarem no mercado produtos com menor margem, têm tendência a gerar menores resultados e, por conseguinte, maiores necessidades de financiamento, justificando-se assim, à luz da POT uma relação positiva com a dívida.

Por último, a reputação das empresas, aferida através da sua idade, parece ser um determinante da estrutura de capital com uma influência negativa no nível de dívida, independentemente da sua maturidade. As PME industriais com mais anos de vida no mercado, registarão maior nível de autofinanciamento e, consequentemente, gerarão menores necessidades de capital alheio. Michaelas et al. (1999) e Palacín-Sánchez et al. (2013) mostram resultados semelhantes. A nível de indústria, é de salientar que todas apresentam uma relação positiva entre a idade e o nível de dívida de maior maturidade, o que não sucede com a dívida de curto prazo, em que em cinco indústrias a longevidade não parece afetar a sua forma de financiamento (têxtil, madeira e cortiça, outros produtos minerais, mobiliário e colchões e outras).

\section{Conclusões}

O presente estudo permite concluir que as características das PME industriais têm diferente relevância na forma como as empresas se financiam e, na sua maior parte, são mais consistentes com a teoria da pecking order. A evidência empírica deste estudo sugere que as empresas aplicam nos seus negócios resultados gerados pelos mesmos, ou seja, manifestam preferência pelo autofinanciamento em detrimento do capital alheio. Não obstante, a situação de crescimento da empresa é geradora de acréscimo de capital alheio, o que poderá ser explicado pela insuficiência de fundos próprios. Acresce que tanto a rendibilidade como o crescimento afetam mais intensamente a dívida de curto prazo do que a de médio e longo prazo. Estes resultados sugerem uma hierarquia de financiamento que coloca a dívida de curto prazo a seguir aos fundos próprios, o que deverá merecer a atenção dos gestores, atendendo a que a dívida de curto prazo acarreta maiores encargos financeiros.

Os resultados obtidos sugerem que no seio das PME industriais, os ativos são importantes no acesso ao crédito de médio e longo prazo, pelo que as empresas mais desprovidas destes colaterais tendem a financiar-se com dívida de curto prazo, o que poderá 
afetar negativamente a sua liquidez e rendibilidade. Estes resultados poderão ser particularmente preocupantes no seio das empresas mais jovens, atendendo à relação negativa esperada entre a idade e a dívida e aos problemas de agência e informação assimétrica entre gestores e credores, comuns nessas empresas.

O efeito observado das indústrias transformadoras parece sugerir que a estrutura de capital das empresas envolvidas não poderá ser exclusivamente explicada pelas características das empresas, mas também pela indústria na qual estão inseridas. A análise inter-indústria revela que diferentes indústrias apresentam diferentes níveis de dívida, como previsto pela teoria do trade-off. Contudo, considerando cada indústria em particular, os resultados também conferem maior consistência à teoria da pecking order. De resto, os modelos de efeitos fixos (AR1) revelaram-se como os mais adequados, sugerindo que a heterogeneidade dentro das indústrias é importante. Os resultados sugerem a existência de fatores intrínsecos às várias indústrias, explicativos da estrutura de capital, o que poderá estimular futura investigação.

A nível de limitações desta pesquisa, é de salientar o período temporal da análise. Com efeito envolveu alguns anos em que Portugal esteve sob intervenção externa, sujeito a políticas de austeridade severa, com reflexos nos níveis de consumo e investimento e, em que as empresas se confrontaram com dificuldades acrescidas de financiamento. Em termos de investigação futura, poder-se-á replicar este estudo num período económico de maior estabilidade económica, aplicando modelos dinâmicos com dados em painel. Será também interessante estudar algumas das indústrias transformadoras, por exemplo a indústria alimentar ou a indústria dos produtos metálicos, que são as mais representativas em número de empresas e volume de negócios, alargando o âmbito do estudo aos efeitos do ciclo de vida.

\section{Referências}

Andraz, G. (2013). Determinantes da dinâmica empresarial: O caso da indústria transformadora portuguesa (Tese de doutoramento não publicada). Universidade de Évora, Évora.

Ang, J. S. (1992). On the theory of finance for privately held firms. The Journal of Small Business Finance, 1(3), 185-203.

Baker, M. \& Wurgler, J. (2002). Market timing and capital structure. The Journal of Finance, 57(1), 1-32. DOI: org/10.1111/1540-6261.00414.

Barnea, A., Haugen, R. \& Senbet, L. (1981). Market imperfections, agency problems, and capital structure: A review. Financial Management, 10(3), 7-22.

Colombo, E. (2001). Determinants of corporate capital structure: Evidence from Hungarian firms. Applied Economics, 33(13), 1689-1701. DOI: 10.1080/00036840010015057.

Degryse, H., Goeij, P. \& Kappert, P. (2012). The impact of firm and industry characteristics on small firms' capital structure. Small Business Economics, 38(4), 431-447. DOI 10.1007/s11187-010-9281-8.

DeAngelo, H. \& Masulis, R. (1980). Optimal capital structure under corporate and personal taxation. Journal of Financial Economics, 8(1), 3-29. DOI: 10.1016/0304-405X(80)90019-7.

Fama, E. F. \& French, K. R. (2002). Testing trade-off and pecking order predictions about dividends and debt. Review of Financial Studies, 15(1), 1-33. DOI: 10.1093/rfs/15.1.1.

Fischer, E., Heinkel, R. \& Zechner, J. (1989). Dynamic capital structure choise: Theory and tests. The Journal of Finance, 44(1), 19-40. DOI: 10.2307/2328273. 
Frank, M. Z. \& Goyal, V. K. (2009). Capital structure decisions: Which factors are reliably important? Financial Management, 38(1), 1-37. DOI: org/10.1111/j.1755-053X.2009.01026.x.

Gujarati, D. \& Porter, D. (2010). Essentials of econometrics. New York: McGrawHill International.

Hall, G., Hutchinson, P. \& Michaelas, N. (2000). Industry effects on the determinants of unquoted SMEs' capital structure. International Journal of the Economics of Business, 7 (3), 297-312. DOI: 10.1080/13571510050197203.

Hall, G., Hutchinson, P. \& Michaelas, N. (2004). Determinants of the capital structures of European SMEs. Journal of Business Finance \& Accounting, 31(5-6), 711- 728. DOI: 10.1111/j.0306686X.2004.00554.x.

Hang, M., Geyer-Klingeberg, J., Rathgeber, A. \& Stöckl, S. (2018). Measurement matters - A meta-study of the determinants of corporate capital structure. The Quarterly Review of Economics and Finance, 68, 211-225. DOI: 10.1016/j.qref.2017.11.011.

Harris, M. \& Raviv, A. (1991). The theory of capital structure. The Journal of Finance, 46(1), 297-355. DOI: 10.1111/j.1540-6261.1991.tb03753.x.

Instituto Nacional de Estatística (INE) (2018). Empresas em Portugal 2016. Lisboa: Instituto Nacional de Estatística.

Jensen, M. C. \& Meckling, W. H. (1976). Theory of the firm: Managerial behavior, agency costs and ownership structure. Journal of Financial Economics, 3(4), 305-360. DOI: 10.1016/0304405X(76)90026-X .

Jensen, M. C. (1986). Agency costs of free cash flow, corporate finance and takeovers. American Economic Review, 76(2), 323-329.

Jordan, J., Lowe, J. \& Taylor, P. (1998). Strategy and financial policy in UK small firms. Journal of Business Finance \& Accounting, 25(1-2), 1-27. DOI: 10.1111/1468-5957.00176.

Kraus, A. \& Litzenberger, R. H. (1973). A state-preference model of optimal financial leverage. The Journal of Finance, 33(4), 911-922. Doi: 10.1111/j.1540-6261.1973.tb01415.x.

Kumar, S., Colombage, S. \& Rao, P. (2015). Research on capital structure determinant's: A review and future directions. International Journal of Managerial Finance, 13(2), 106-132. DOI: 10.1108/JJMF-09-2014-0135.

Leland, H. \& Pyle, D. (1977). Informational asymmetries, financial structure, and financial intermediation. The Journal of Finance, 32(2), 371-387.

López-Gracia, J. \& Sogorb-Mira, F. (2008). Testing trade-off and pecking order theories financing SMEs. Small Businesss Economics, 31(2), 117-136. DOI: 10.1007/s11187-007-9088-4.

Margaritis, D. \& Psillaki, M. (2010). Capital structure, equity ownership and firm performance. Journal of Banking and Finance, 34(3), 621- 632. DOI: 10.1016/j.jbankfin.2009.08.023.

Matias, F., Baptista, C. \& Salsa, L. (2015). Estrutura do capital das PME da indústria transformadora portuguesa: Uma análise com dados em painel. Tourism \& Management Studies, 11(2), 120-129. DOI: 10.18089/tms.2015.11215.

Michaelas, N., Chittenden, F. \& Poutziouris, P. (1999). Financial policy and capital structure choice in U.K. SMEs: Empirical evidence from company panel data. Small Business Economics, 12(2): 113-130. DOI: 10.1023/A:1008010724051.

Miller, M. H. (1977). Debt and taxes. The Journal of Finance, 32(2), 261-275. DOI: 10.1111/j.15406261.1977.tb03267.x.

Modigliani, F. \& Miller, M. H. (1958). The cost of capital, corporation finance and the theory of investment. The American Economic Review, 48(3), 261-297. 
Modigliani, F. \& Miller, M. H. (1963). Corporate income taxes and the cost of capital: A correction. The American Economic Review, 53(3), 433-443.

Myers, S. C. (1977). Determinants of corporate borrowing. Journal of Financial Economics, 5(2), 147-175. DOI: 10.1016/0304-405X(77)90015-0.

Myers, S. C. (1984). The capital structure puzzle. The Journal of Finance, 39(3), 575-592. DOI: 10.1111/j.1540-6261.1984.tb03646.x.

Myers, S. C. (1993). Still searching for optimal capital structure. Journal of Applied Corporate Finance, 6(1), 4-14. DOI: 10.1111/j.1745-6622.1993.tb00369.x.

Myers, S. C. \& Majluf, N. S. (1984). Corporate financing and investment decisions when firms have information that investors do not have? Journal of Financial Economics, 13(2), 187-221. DOI: 10.1016/0304-405X(84)90023-0.

Palacín-Sánchez, M., Ramírez-Herrera, L. \& Pietro, F. (2013). Capital structure of SMEs in Spanish regions. Small Business Economics, 41(2), 503 - 519. DOI: 10.1007/s11187-012-9439-7.

Ramalho, J., Rita, R. \& Silva, J. V. (2018). The impact of family ownership on capital structure of firms: Exploring the role of zero-leverage, size, location and the global financial crisis international small business. Researching Entrepreneurship, 36(5) 574-604. DOI: 10.1177/0266242617753050.

Serrasqueiro, Z., Armanda, M. \& Nunes, P. (2011). Pecking order theory versus trade-off theory: Are service SMEs' capital structure decisions different? Service Business, 5(4), 381-409. DOI 10.1007/s11628-011-0119-5.

Serrasqueiro, Z., Matias, F. \& Salsa, L. (2016). Determinants of capital structure: New evidence from Portuguese small firms. Dos Algarves: A Multidisciplinary e-Journal, 28, 13-28. DOI: 10.18089/DAMeJ.2016.28.2.

Showalter, D. (1999). Strategic debt: Evidence in manufacturing. International Journal of Industrial Organization, 17, 319-333. DOI: 10.1016/S0167-7187(97)00030-1.

Shyam-Sunder, L. \& Myers, S. (1999). Testing static tradeoff against pecking order models of capital structure. Journal of Financial Economics, 51(2), 219-244. Doi: 10.1016/S0304-405X(98)00051-8.

Titman, S. \& Wessels, R. (1988). The determinants of capital structure choice. The Journal of Finance, 43(1), 1-19. DOI: 10.1111/j.1540-6261.1988.tb02585.x.

Voulgaris, F., Asteriou, D. \& Agiomirgianakis, G. (2002). Capital structure, asset utilization, profitability and growth in the Greek manufacturing sector. Applied Economics, 34(11), 1379-1388. DOI: 10.1080/00036840110096822.

Zhang, Y. (2010). The product category effects on capital structure: Evidence from the SMEs of British manufacturing industry. International Journal of Business and Management, 5(8), 86-112. DOI: $10.5539 / \mathrm{ijbm} . v 5 \mathrm{n} 8 \mathrm{p} 86$.

FERNANDA MATIAS é doutorada em Finanças Empresariais pelo Instituto Superior das Ciências do Trabalho e da Empresa (ISCTE). É Professora Coordenadora da Escola Superior de Gestão, Hotelaria e Turismo da Universidade do Algarve (UAlg), coordenadora da unidade curricular de Matemática Financeira e diretora do Curso Superior de Gestão. Integra o CEFAGE e publica na área das finanças empresariais. Exerceu funções na Reitoria, tendo sido Vice-Reitora durante 8 anos. É coautora do livro de Finanças Empresariais. A sua atividade de ensino e formação profissional desenvolveu-se para além da UAlg, nomeadamente no ISCTE, no Instituto de Emprego e Formação Profissional e no Instituto de Formação Bancária. Exerceu funções de direção financeira. Endereço institucional: Departamento de Gestão Financeira, Universidade do Algarve, Escola Superior de Gestão, Hotelaria e Turismo, Faro 8005-139, Portugal. 
LETÍCIA DOMINGUES é mestre em Finanças Empresariais pela Faculdade de Economia (UAlg) e licenciada em Gestão pela Escola Superior de Gestão, Hotelaria e Turismo (UAlg). Atualmente exerce funções de controlo de crédito numa empresa de média dimensão, exerceu também funções no apoio à gestão de fornecedores. Fez um estágio curricular no Crédito Agrícola e um extracurricular no grupo de hotéis Vila Galé. Endereço institucional: Departamento de Gestão Financeira, Universidade do Algarve, Escola Superior de Gestão, Hotelaria e Turismo, Faro 8005-139, Portugal.

Submetido em 8 julho 2019

Aceite em 21 outubro 2019 